\title{
Editorial
}

\section{Best Geosynthetics International Paper for 2017}

Geosynthetics International is an official journal of the International Geosynthetics Society (IGS) and serves the mandate of the society to disseminate important technical developments to its members.

We are delighted to announce the best paper in Volume 24 (2017) based on votes cast by the Editorial Board Members. In this annual competition, the Editor and Editorial Board Chairman are not eligible for this award and do not vote.

The 'Best Geosynthetics International Paper for 2017' award goes to:

Dixon, N., Fowmes, G. and Frost, M. (2017). Global challenges, geosynthetic solutions and counting carbon. Geosynthetics International, 24, No. 5, 451-464.

The following paper was selected for runner-up and thus receives honourable mention as 'one of the best papers published in Geosynthetics International in 2017':

Koerner, R. M., Hsuan, Y. G. and Koerner, G. R. (2017). Lifetime predictions of exposed geotextiles and geomembranes. Geosynthetics International, 24, No. 2, 198-212.

We thank the members of the Editorial Board for participating in the best paper selection process and congratulate the authors of these excellent papers. Each paper reflects the high standards of the Journal and is an important contribution to our geosynthetics discipline. All IGS members have free access to these papers, as they have free access to all papers published in the Journal.

Geosynthetics International is published by Thomas Telford Ltd.

R. J. Bathurst, Editor J. P. Giroud, Chairman of the Editorial Board 